\title{
Head-centered representation and spatial memory in rat posterior parietal cortex
}

\author{
LONGTANG L. CHEN \\ Northwestern University Medical School, Chicago, Illinois \\ and \\ KIYOMI NAKAMURA \\ Toyama Prefectural University, Toyama, Japan
}

\begin{abstract}
Rodent posterior parietal cortex, similar to its homologue in primates, has been shown to be critically involved in spatial navigation. We summarize here selected neurophysiological data and their relevance to recent lesion-behavioral studies. The findings indicate that the rat posterior parietal cortex contains a significant proportion of neurons that code for head-centered (or body-centered) space by making use of the vestibular and proprioceptive inputs. Some posterior parietal neurons may store a working representation of space, which appears to be allocentric.
\end{abstract}

Rodent cortex is thought to be organized in a general scheme similar to that in primates. The rat occipital cortex, similar to its counterpart in the primates, sits posterior to the parietal cortex (Zilles, 1985, 1990). Past studies have shown that an area sandwiched between the rat primary visual cortex (Oc1) and somatosensory cortex (Par 1) is an associative cortex, possibly a homologue of primate posterior parietal cortex (Kolb, 1990; Krieg, 1946; Reep, Chandler, King, \& Corwin, 1994). This region has been given a multitude of names, such as Krieg area 7 (Krieg, 1946), area $A M$ (Olavarria \& Montero, 1981), and rostral prestriate Oc2M (rostral Oc2MM and Oc2ML; Zilles, 1985). In this paper, the rat posterior parietal cortex will be referred to as area $O c 2 M$. This by no means implies that this area is primarily a prestriate visual area. In fact, it has been shown that this region integrates multimodal inputs: visual, somatosensory, and auditory inputs (Miller \& Vogt, 1984; Toldi, Foher, \& Wolff, 1986; Vogt \& Miller, 1983). A significant proportion of the Oc2M cells appeared to show complex visual-sensorimotor associative characteristics; the visuomotor activity persisted even in the absence of the salient visual cues (Chen, Lin, Barnes, \& McNaughton, 1994b).

Rat posterior parietal cortex has been shown to be critically involved in guiding spatial navigation, directing spatial attention, and forming spatial memory (Crowne, Richardson, \& Dawson, 1989; see Kolb, 1990, for review). Previous lesion-behavioral studies have indicated that a

Part of this work was supported by PHS Grant NS20331 and Science and Culture Grants-in-Aid 06260234 and 05808800 , Japan. The authors are grateful for the support of J. C. Houk, B. L. McNaughton, and C. A. Barnes; helpful comments of two anonymous referees; and editorial assistance of Barbara Smith. Correspondence should be addressed to L. L. Chen, Department of Physiology, Northwestern University Medical School, Ward 5-150, 303 Chicago Ave., Chicago, IL 60611-3008 (e-mail: longtang@nwu.edu). lesion of posterior parietal cortex produces profound deficits in visuospatial discrimination and spatial navigation (DiMattia \& Kesner, 1988a, 1988b; Kesner, Farnsworth, \& DiMattia, 1989; Kolb, Buhrmann, McDonald, \& Sutherland, 1994; Kolb \& Walkey, 1987; Long \& Kesner, 1996; McDaniel \& Skeel, 1993; Sanchez et al., 1997; Save, Poucet, Foreman, \& Buhot, 1992). The deficit in spatial working memory has been consistently demonstrated to be a major symptom in rats whose parietal cortex was lesioned (Cho \& Kesner, 1996; Kametani \& Kesner, 1989; Kesner, Farnsworth, \& Kametani, 1992; Kolb et al., 1994; Poucet \& Benhamou, 1997; Save \& Moghaddam, 1996). Thus, overwhelming lesion-behavioral evidence has suggested that some forms of spatial information must be processed and temporarily stored in this area. However, the neurophysiological basis supporting these functions remains poorly understood.

There are two approaches to studying the neurophysiology of sensory and spatial information processing. The first approach, as has been adopted widely in freely moving rodent experiments, is to allow the animals to travel across space. This quasi-ethological approach provides an opportunity for the experimenters to observe spatially selective responses of neurons, such as "place" cells (O'Keefe \& Dostrovsky, 1971) or "head-direction" cells (Knierim, Skaggs, Kudrimoti, \& McNaughton, 1996; Ranck, 1984; see McNaughton et al., 1996). The alternate approach is to restrain the animals' mobility, then study the neural responses while the spatial cues were presented around the animals (Andersen, Snyder, Bradley, \& Xing, 1997; Brotchie, Andersen, Snyder, \& Goodman, 1995; Galletti, Battaglini, \& Fattori, 1993; Mountcastle, Lynch, Georgopoulos, Sakata, \& Acuna, 1975; Sakata, Taira, Kusunoki, Murata, \& Tanaka, 1997). The latter approach is widely adopted in primate studies but is less common in rodent studies. In the following sections, we will focus on some selected neurophysiological studies that have employed 

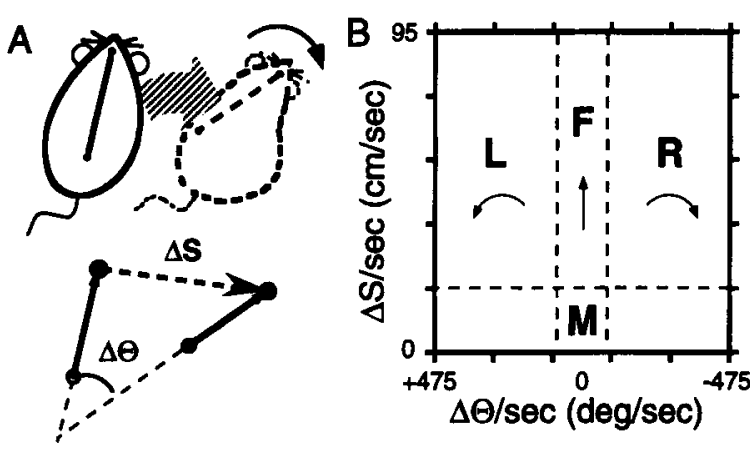

Figure 1. Experimental design for tracking rat's head orientation and position. (A) Schematic drawing of the dual-LED rod mounted on the rat's head. When the rat was in motion, its head displacement $(\Delta S)$ and head-angle displacement $(\Delta \Theta)$ could be extrapolated on the basis of the LED trajectories. (B) The velocity cutoffs for distinctive modes of motion. $F$, forward motion; $L$, left turns; $M$, motionless or nonlocomotive mode; $R$, right turns. Note-From "Head-Direction Cells in the Rat Posterior Cortex: I. Anatomical Distribution and Behavioral Modulation," by L. L. Chen, L.-H. Lin, E. J. Green, C. A. Barnes, and B. L. McNaughton, 1994, Experimental Brain Research, 101, p. 13. Copyright 1994 by Springer-Veriag. Adapted with permission.

the two approaches to study the function of rat posterior parietal cortex.

\section{EXPERIMENTAL DESIGN FOR STUDYING THE FREELY MOVING RODENTS}

Chen, Lin, Green, Barnes, and McNaughton (1994) designed a dual-light-emitting-diode (LED) head-tracking system to study the activity of rat cortical neurons. In their design, the rat's head was mounted with a rod containing dual LEDs (Figure 1A; BrainWave System Corp.). The
LED positions, sequential in time, could then be extrapolated to reflect the linear and angular velocities of the head trajectories. When the two velocity profiles were plotted in an orthogonal manner during movements, various modes of motion could be objectively teased apart with reasonable confidence. The modes of motion include angular motion (left and right turns), forward motion, and motionless (Figure 1B).

The rats were trained to perform the spatial working memory task on a radial eight-arm maze (Olton \& Samuelson, 1976). The maze had small aluminum containers at the end of each arm, one of each was baited with chocolate milk. The maze arms were baited once per trial. The rats had to remember not to visit the same arm more than once in order to maximize the reward rates. Spatial cues must be properly controlled in order to draw useful conclusions from the freely moving rats (Chen, Lin, Barnes, \& McNaughton, 1994b). The maze room was painted black, providing the minimal reflectance of the wall. The maze was lit symmetrically by a single reflector light bulb mounted on the center of the ceiling. Black and white cardboard panels were placed around the maze as controlled visual cues. These cues gave some degree of reflectance of light $\left(2.5-5 \mathrm{~cd} / \mathrm{cm}^{2}\right)$, but the remainder of the room was poorly lit. Also, the visual cue panels were manipulated when the light was turned out. This prevented the animals from keeping track of the visual cue manipulation.

\section{REPRESENTATION OF HEAD ORIENTATION}

Some posterior parietal neurons have been found to respond selectively to the animal's head orientation (Figure 2A; Chen, Lin, Green, et al., 1994). These "head-
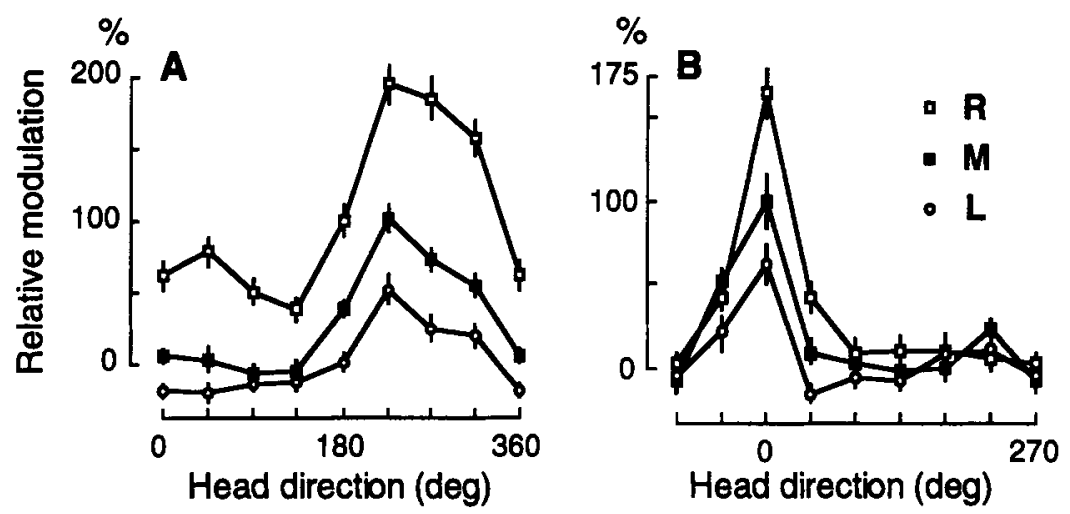

Figure 2. Cells whose activities were modulated by head orientation and body motion for (A) Oc2M and (B) RSA. In the plots, $100 \%$ modulation indicates the maximal firing rate for the motionless mode in the preferred direction, whereas $0 \%$ refers to the mean rate for the same mode in the four nonpreferred directions. Note that the modulation can go from $50 \%$ to $200 \%$, depending on the mode of angular motion. Error bars represent SEMs. Note-From "Head-Direction Cells in the Rat Posterior Cortex: I. Anatomical Distribution and Behavioral Modulation," by L. L. Chen, L.-H. Lin, E. J. Green, C. A. Barnes, and B. L. McNaughton, 1994, Experimental Brain Research, 101, p. 18. Copyright 1994 by Springer-Verlag. Adapted with permission. 

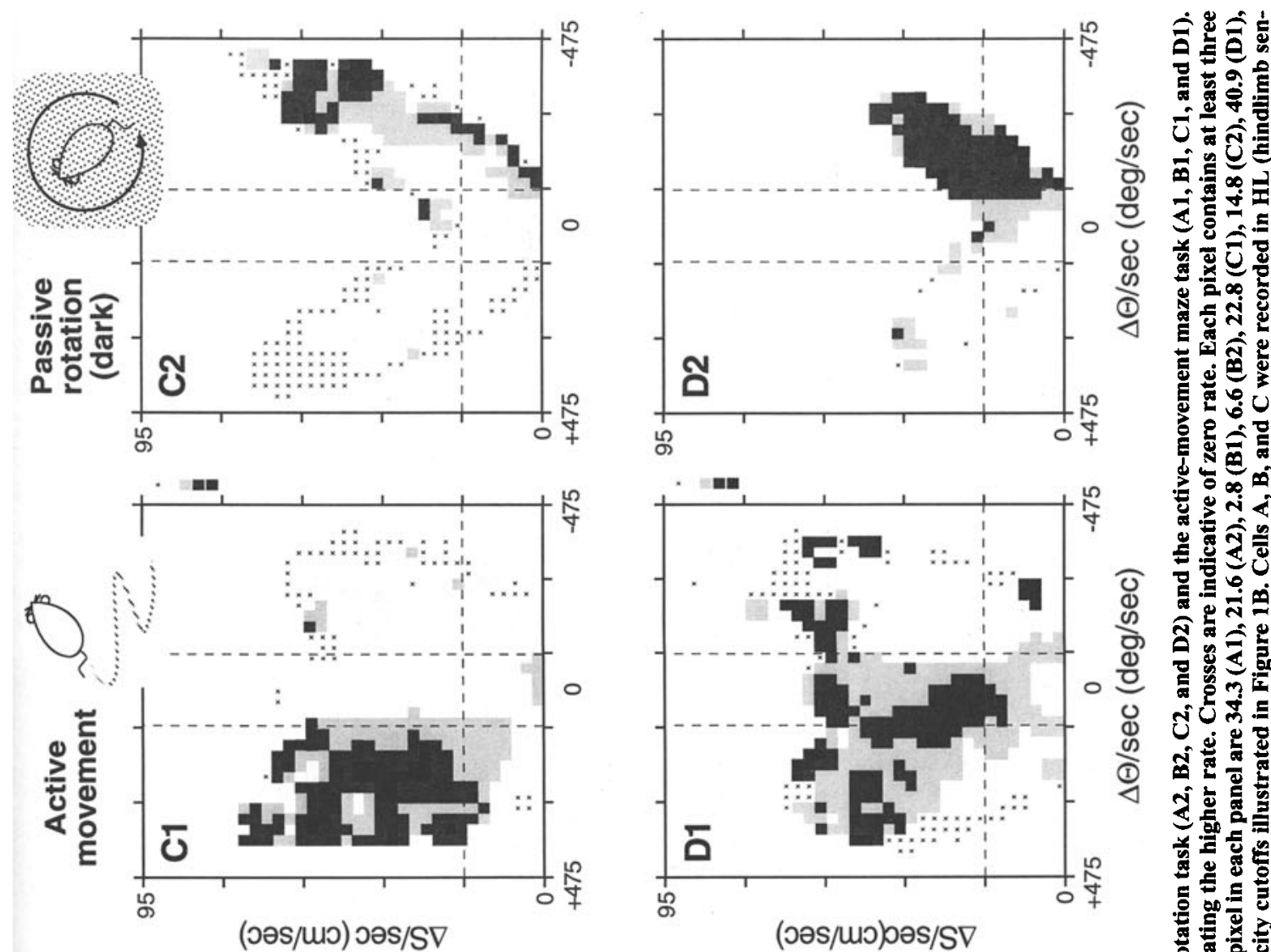

올을 占象象

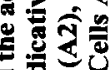

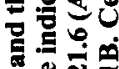
ลิธ 울 กิบ政

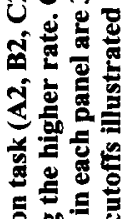
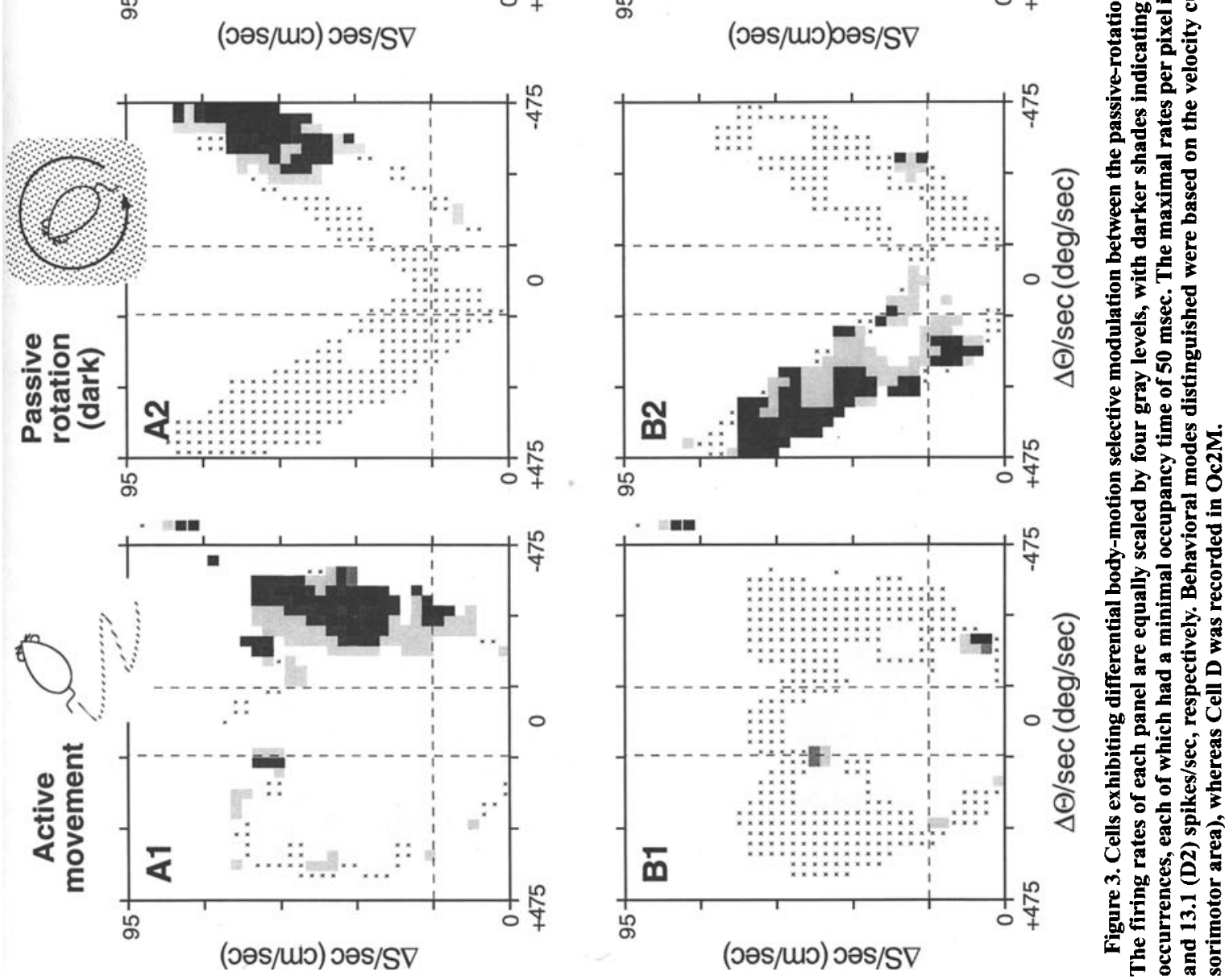


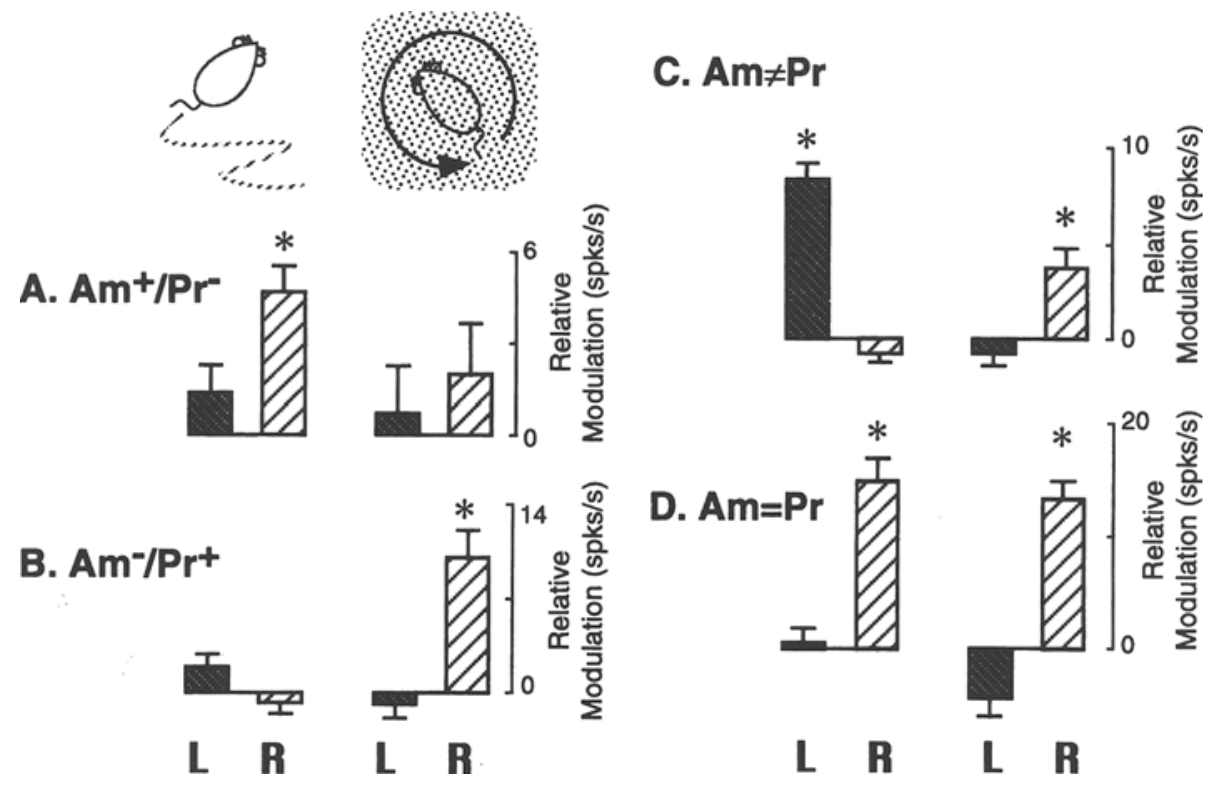

\begin{abstract}
Figure 4. Modulation of angular motions in different task conditions: active movement on a maze task (left panels) and passive rotation in the dark (right panels). The bar charts are plotted as relative modulation from the mean rates for motionless mode. Error bars represent $S E M$ s. The asterisks indicate statistical significance in the comparison of a given angular motion modulation with that of motionless (Mann-Whitney $U, p<.01$ ). Am, active movement; $\mathrm{Pr}$, passive rotation in the dark; $L$, left turns; $R$, right turns. Cells $A$ and $C$ were recorded in $O c 2 M$, Cell B in HL, and Cell D in RSA.
\end{abstract}

direction" cells were named after Ranck's terminology, because these cells exhibited a head-orientation selective discharge (Ranck, 1984). Head-direction cells are also found in paralimbic cortices: postsubiculum and dysgranular (RSA) and granular (RSG) retrosplenial cortex, as well as other brain regions that are connected to these areas (Blair \& Sharp, 1996; Chen, Lin, Green, et al., 1994; McNaughton, Chen, \& Markus, 1991; Mizumori \& Williams, 1993; Ranck, 1994; Taube, Muller, \& Ranck, 1990). Like the head-direction cells observed in the paralimbic regions (e.g., RSA; see Figure 2B), the headdirection cells in the posterior parietal cortex retained their directional biases either in the dark or after the removal of the controlling cues (Chen, Lin, Barnes, \& McNaughton, 1994b).

Some head-direction cells appeared to associate angular motions with head orientation. As shown in Figure $2 \mathrm{~A}$, the most significant modulation took place for the right turns, whereas the modulation was suppressed for the left turns. This indicates that these cells keep tracking the head orientation by integrating the angular motion information. McNaughton et al. (1991) hypothesized that the vestibular inputs can help "read out" the projected head-direction ensemble. That is, the activation of head-direction ensemble is determined by the conjunctive activation of an initial head-direction ensemble and the angular displacement, which is calculated on the basis of vestibular inputs (e.g., integral of an- gular velocity). For instance, the activation of a $180^{\circ}$ head-direction ensemble results from the activation of a $90^{\circ}$ head-direction ensemble plus a $90^{\circ}$ turn. Such a mechanism can serve to track the head orientation without referencing to external sensory inputs (such as in total darkness). This hypothesis has been supported by recent studies that showed that vestibular manipulations or lesions significantly influence the head-direction tuning (Blair \& Sharp, 1996; Stackman \& Taube, 1997). However, the hypothesis (McNaughton et al., 1991) assumes that the head-direction cells form reverberating circuits and that the vestibular inputs must be widely distributed among the head-direction cells. So far, there have been no experiments aimed at elaborating the anatomical connections supporting the notion of the reverberating circuitry. Moreover, multiple sensorimotor inputs are compounded in behaving animals. One cannot simply equate the angular motion correlates, observed in freely moving animals, as the vestibular contribution. If the posterior parietal cortex contributes to the head-direction spatial processing, it would be important to know what information the cortex contributes.

\section{ANGULAR MOTION MODULATION AND VESTIBULAR INPUTS}

It should be noted that the head-direction cells in the posterior parietal cortex are rare- $3 \%$ of the total cells 
sampled (Chen, Lin, Green, et al., 1994). Motor efference copies, presumably widely present in the posterior parietal cortex, may provide more general spatial signals help animals navigate through space (Chapin \& Woodward, 1986; Chen, Lin, Barnes, \& McNaughton, 1994b; Hyvärinen, 1982; McNaughton et al., 1994; Neafsey et al., 1986; Wise \& Donoghue, 1986). Thus, these headdirection cells may represent a fraction of the neuronal population that code for various spatial maps, possibly by making use of the available sensory inputs in order to meet different goals of action s, such as escaping from potential predators, reaching for prey or objects, or navigating through space (Andersen et al., 1997; Duhamel, Bremmer, BenHamed, \& Graf, 1997; Goodale \& Milner, 1992; Jennerod, Arbib, Rizzolatti, \& Sakata, 1995; Sakata et al., 1997; Snyder, Batista, \& Andersen, 1997). Various sources of sensorimotor inputs could provide spatial information to cells of the posterior parietal cortex, including head-direction cells. One type of spatial information is angular motion modulation, which possibly reflects an elementary, explicit head-centered (or bodycentered) spatial coding (e.g., left vs. right). Whether or not the majority of the posterior cortical neurons code for the angular motion on the basis of vestibular inputs has been a critical issue, because the vestibular inputs could serve as a read-out mechanism for the head-directional representation (McNaughton et al., 1991).

Chen, Lin, Barnes, and McNaughton (1994a, 1994b) have taken advantage of the angular motion analysis and attempted to examine the angular motion signal in passive rotation conditions compared with that during active movements. The former should be driven primarily by vestibular inputs (plus possibly the proprioceptive inputs), whereas the latter should be driven by various compounded active movement inputs and higher cognitive processes. The active-movement maze task was as described in the previous section. The passive-rotation task was carried out using a modified "lazy Susan," in which the rats sat still throughout the period, with the light turned out. The rats were placed in the middle of the lazy Susan tray; the tray had woodblock "fences" on the sides to help animals stand firm. The experimenter then moved around the tray and rotated the platform in clockwise and counterclockwise directions alternately. The task paused randomly for $1-3 \mathrm{sec}$ between rotations. The angle of each rotation was $120^{\circ}-200^{\circ}$ at a speed of $30-50 \mathrm{rpm}$. This experiment was carried out either immediately before or after the maze task; the same units were retained for tests. Note that, in such a passive-rotation manipulation, the animals were devoid of visual inputs and most of the sensorimotor inputs that were present in freely moving animals. The angular motion correlates could then be attributed primarily to vestibular contribution. Some proprioceptive inputs might have been involved when the animals adjusted their own postures during the rotations.

It was found that, in some cells in the posterior parietal cortex, the active movements could significantly alter the neural activity pattern; the neuronal responses of these cells during the passive-rotation task were dramatically different from those during the active-movement task. Figure 3 illustrates examples in which cells exhibited apparently different activity modulation in response to different angular motion. Figure 4 illustrates the average modulation rates for different modes of motion in different tasks. The angular motion correlates are measured relative to those of motionless mode. Head-direction, visuomotor, and illuminance-sensitive cells were excluded from the analysis. The modulation can be categorized into four types: (1) $\mathrm{Am}^{+} / \mathrm{Pr}^{-}$, cells that were active exclusively during the active movement; (2) $\mathrm{Am}^{-} / \mathrm{Pr}^{+}$, cells (e.g., Figures $3 \mathrm{~B} 1$ and $3 \mathrm{~B} 2$ ) that were exclusively active during the passive rotation; (3) Am $\neq$ Pr, cells (e.g., Figures $3 \mathrm{Cl}$ and $3 \mathrm{C} 2$ ) that were active during both tasks, but the modulation differed in the signs of angular motion (i.e., left vs. right turns); and (4) $\mathrm{Am}=\mathrm{Pr}$, cells (e.g., Figures $3 \mathrm{~A} 1$ and $3 \mathrm{~A} 2$ ) that showed similar modulation in both tasks. The remainder were unmodulated cells (i.e., $\mathrm{U}$ or $\mathrm{Am}^{-} / \mathrm{Pr}^{-}$) that were not selective for either of the angular motions. Figure 5 illustrates the proportional distribution of these cells in areas Oc2M, HL (hindlimb sensorimotor area; Zilles, 1985), RSA, and RSG. Note that HL contains the vast majority $(80 \%)$ of cells selective for angular motions. This proportion is reduced to $60 \%$ in Oc2M, $51 \%$ in RSA, and $46 \%$ in RSG. Also, the proportion of the fourth type of cells (i.e., $\mathrm{Am}=\mathrm{Pr}$ ), whose angular motion correlates can be accounted for

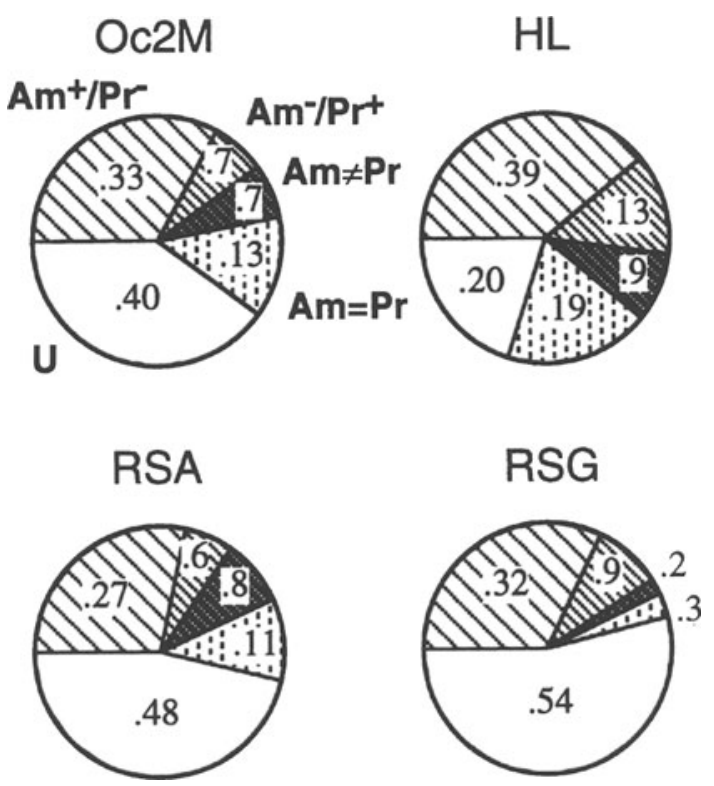

Figure 5. Percentile distribution of cells classified on the basis of their activity modulation in the active movements and passive rotations. Total cells tested were 30 in Oc2M, 75 in HL, 66 in RSA, and 63 in RSG. Am, active movement; Pr, passive rotation in the dark; $U$, unmodulated. Same classification scheme as in Figure 4. Note that the cells exhibiting directional biases (i.e., head-direction cells, visuomotor cells, and illuminance-sensitive cells) were excluded from the plots. 


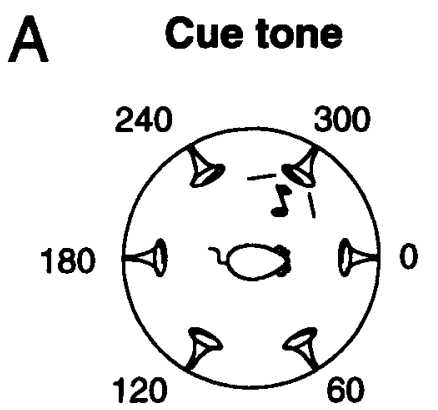

Delay

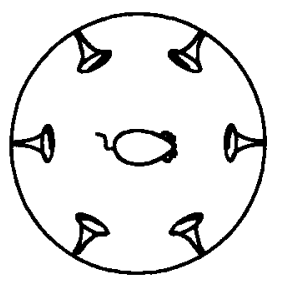

Testing tone

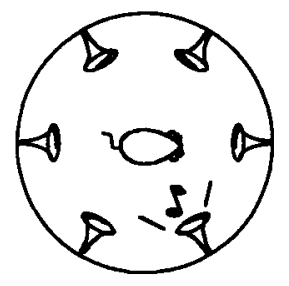

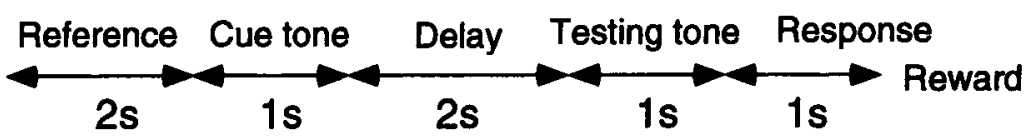

B
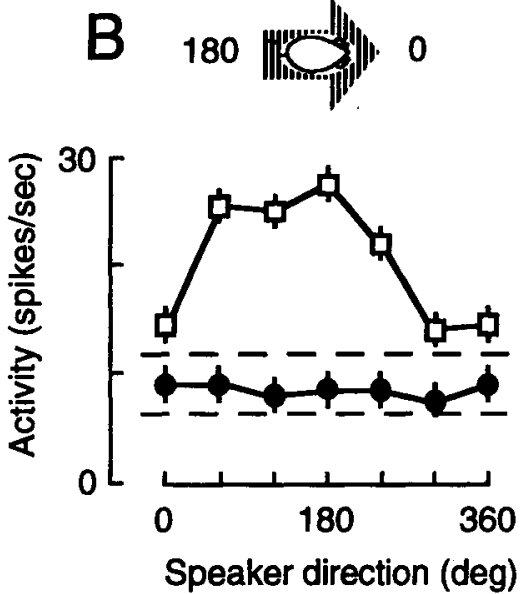
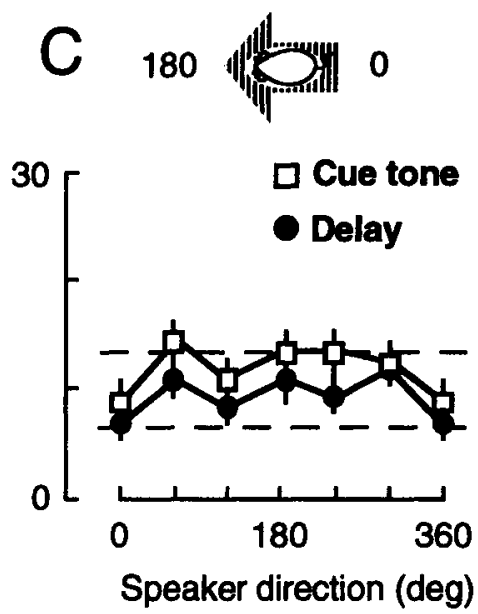

Figure 6. An Oc2M cell discriminating for spatial tones. (A) The experimental setup, in which 6 speakers were placed around the rats, is illustrated at the top of the panel. Task epochs and sequence of tone presentation are plotted below. (B) Histograms illustrating the cell's response to directional tones during the cue-tone period (open square) and during the delay period (filled circles) in which no tone was present. Dash lines indicate $\pm 1 S D$ of the activity in the reference epoch. Error bars represent SEMs. (C) Similar measurement, except the rat was reoriented toward the $180^{\circ}$ direction.

primarily by vestibular and proprioceptive inputs, were significantly reduced from $19 \%$ in $\mathrm{HL}$ to $13 \%$ in Oc2M to $11 \%$ in RSA and to $3 \%$ in RSG. These differences are striking, and they appear to suggest that the vestibular/proprioceptive influence constitutes only a small portion of the angular motion signals in the paralimbic areas, in which the angular motion signals are also significantly deemphasized. Given that the angular motion correlate is a measure of an explicit head-centered (or body-centered) spatial coding, the paralimbic coding strategy of space would be far from a head-centered framework. Unlike the paralimbic areas, the posterior parietal cortex appears to have a significant proportion of neurons relying on the vestibular/proprioceptive inputs to code for the head-centered (or body-centered) space.

Note also that active-movement inputs often override the passive-motion inputs (i.e., $\mathrm{Am}^{+} / \mathrm{Pr}^{-}, \mathrm{Am}^{-} / \mathrm{Pr}^{+}$, and
Am $\neq$ Pr; e.g., Figures 3B-3D). Such an active-movement modulation is widely spread among these areas. This active-movement gating phenomenon has been demonstrated previously in the somatosensory areas, in which the motor efference copies often inhibit the sensory inputs, rather than excite them (Chapin \& Woodward, 1981, 1986). Such a gating mechanism may serve to distinguish the subject's own body movement from the motion of the surroundings (e.g., visual motion-vestibular or vestibular-proprioception interactions; see Keshner \& Peterson, 1995; Peterson, Baker, Perlmutter, \& Iwamoto, 1992; Sakata et al., 1997; Tanaka et al., 1986).

\section{MEMORY FOR SPATIAL DIRECTIONS}

Nakamura and colleagues (Nakamura, Miyamoto, Kinoshita, \& Ohzawa, 1997; Nakamura, Ono, Isaji, \& 
Yoshida, 1995) took a different approach to study the rat posterior parietal cortex. In their task design, the rats, with their heads fixed, were seated comfortably in the middle of a room. Figure $6 \mathrm{~A}$ illustrates the basic elements of their setups and task flows. Six loudspeakers, placed $60^{\circ}$ apart from each other and $1 \mathrm{~m}$ from the rat, were used as directional probes. The direction-testing apparatus was enclosed in hexagon-shaped walls surrounding the rats. This setup removed the influence of the remote cues.

The rats were trained to perform a directional delayedmatching-to-sample (or nonmatching-to-sample) task. A cue tone $(1000 \mathrm{~Hz}$ and $90 \mathrm{~dB}$ SPL) was first given in a particular loudspeaker; this was followed by a 2 -sec delay period. Then, a second testing tone of the same frequency and amplitude was presented in either the same (matching) loudspeaker or a different (nonmatching) one. The rats were required to lick a spout to receive the reward in one of the two conditions immediately following a nonmatched testing tone or were required to postpone the licking (for $1 \mathrm{sec}$ ) after the matched ones. The reward, in this case, was an electrical-stimulating pulse given to the rat's lateral hypothalamus. A trained rat could perform at above $85 \%$ correct level.

Figure $6 \mathrm{~B}$ illustrates an $\mathrm{Oc} 2 \mathrm{M}$ cell that was selective for directional tones. The cell exhibited a robust modulation in response to the tones presented at $60^{\circ}-240^{\circ}$, whereas it showed no directional bias during the delay period in which the cue tones were absent. Reorienting the rat by $180^{\circ}$ completely abolished the directional discharge of this cell (Figure 6C). This indicates that the cell's directional response was gated by the animal's visual views or possibly head (or body) orientation in allo- centric space. This type of cell constitutes about a quarter $(26 \%)$ of the total cells examined.

Among the cells that responded to directional tones, over two thirds were particularly interesting. Their responses appeared to carry some mnemonic values. Figure $7 \mathrm{~A}$ illustrates an $\mathrm{Oc} 2 \mathrm{M}$ cell that exhibited robust response during the cue-tone period as well as during the delay period. This suggests that the cell was capable of retaining the spatial information for a short period, at least lasting through the delay period, in which the cue tones were no longer present. Strikingly, such a directional preference persisted even after the rat was reoriented $180^{\circ}$ away from the original direction (Figure 7B). The directional response persisted through the delay period. The results together support the notion that the posterior parietal cortex processes directional memory that can be allocentric in nature in the testing environment (Cho \& Kesner, 1996; Long \& Kesner, 1996; Poucet \& Benhamou, 1997; Save \& Moghaddam, 1996).

Whether such apparent mnemonic responses are acquired through experience, such as those in other parts of the brain (Chen \& Wise, 1995a, 1995b, 1996, 1997; Mitz, Godschalk, \& Wise, 1991; Miyashita, Sakai, \& Hikosaka, 1996; Wise, Chen, \& Dominey, 1996), remains open for future studies.

\section{CONCLUDING REMARKS}

We conclude that the rat posterior parietal cortex, similar to its homologue in primates, is a multimodal integrator. A significant proportion of the posterior parietal neurons codes for a head-centered (or body-centered) space on the basis of the vestibular/proprioceptive inputs.
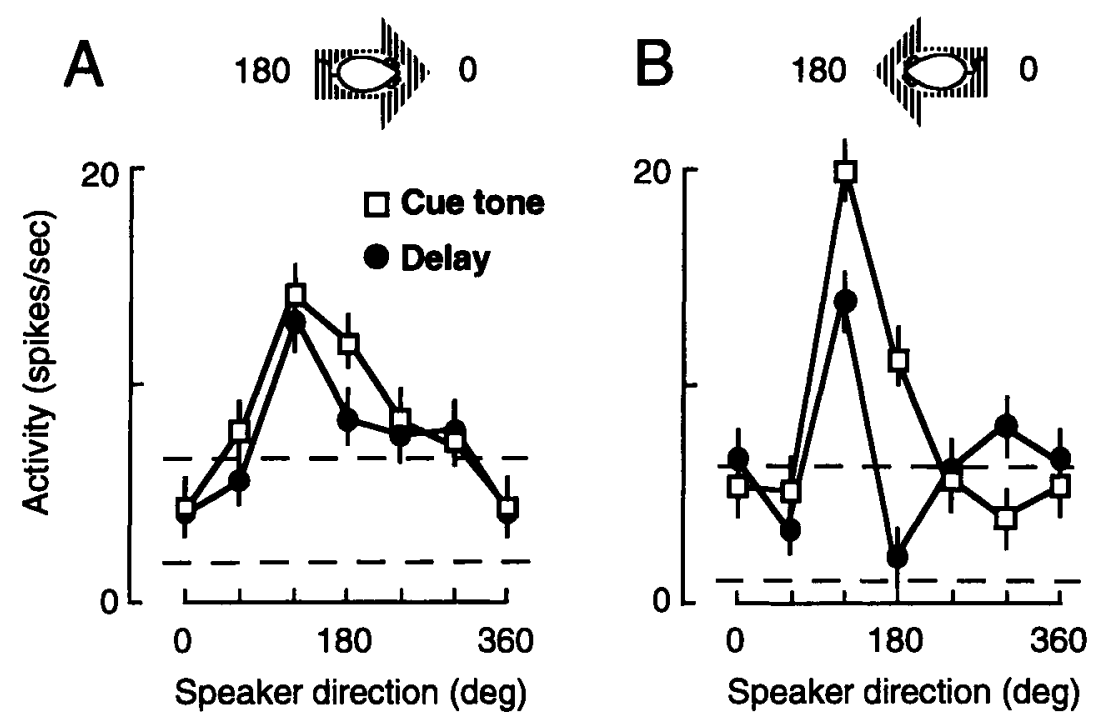

Figure 7. An Oc2M cell exhibiting apparent memory for the cue-tone directions during the delay period. Note that the directional tunings of this cell remained unchanged for the cue-tone and delay epochs. Such a directional response was unaltered even after the rat's head was reoriented toward the $180^{\circ}$ direction. Format same as in Figure 6. 
This is in sharp contrast to the paralimbic neurons, which tend to rely less on vestibular or proprioceptive information. It is thus unlikely that vestibular/proprioceptive inputs serve as a "vestibular reflex" type of read-out interface for the head-direction cells, especially in the paralimic regions. Nevertheless, it is likely that some residual of vestibular influence is passed on to those regions either through the posterior parietal cortex or other routes. The information passed on may be gated by other mechanisms not yet determined. This would explain the results in which the vestibular manipulations tend to produce significant influence on the head-directional activity; however, the effects were often inconsistent and somewhat unpredictable. The same manipulation may produce more consistent results in the posterior parietal head-direction cells, since the posterior parietal cortex is more directly involved in the vestibular and proprioceptive processing (Fukushima, 1997).

Spatial memory representation in the posterior parietal cortex is complex. Some posterior parietal neurons appear to store an allocentric, working representation of the spatial tones, regardless of body orientation. This leads to the possibility that the posterior parietal cortex reconstructs an allocentric representation by combining the available head-centered or body-part-centered information that it processes (Nakamura \& Takarajima, 1996; Pouget \& Sejnowski, 1997). The reconstruction and consolidation of such an allocentric representation may be via the help of the paralimbic inputs (McClelland, McNaughton, \& O'Reilly, 1995).

\section{REFERENCES}

Andersen, R. A., Snyder, L. H., Bradley, D. C., \& XING, J. (1997). Multimodal representation of space in the posterior parietal cortex and its use in planning movements. Annual Review of Neuroscience, 20, 303-330.

BLAIR, H. T., \& ShaRP, P. E. (1996). Visual and vestibular influences on head-direction cells in the anterior thalamus of the rat. Behavioral Neuroscience, 110, 643-660.

Brotchie, P. R., ANDERSEn, R. A., SNyder, L. H., \& GoOdMan, S. J. (1995). Head position signals used by parietal neurons to encode locations of visual stimuli. Nature, 375, 232-235.

Chapin, J. K., \& WoodWaRd, D. J. (1981). Modulation of sensory responsiveness of single somatosensory cortical cells during movement and arousal behaviors. Experimental Neurology, 72, 164-178.

ChapIN, J. K., \& WoOdWARD, D. J. (1986). Distribution of somatic sensory and active-movement neuronal discharge properties in the MI-SI cortical border area in the rat. Experimental Neurology, 91, 503-523.

Chen, L. L., Lin, L.-H., Barnes, C. A., \& McNaughton, B. L. (1994a). [Behavioral modulation of cells in rat posterior cortices.] Unpublished raw data.

Chen, L. L., Lin, L.-H., Barnes, C. A., \& McNaughton, B. L. (1994b). Head-direction cells in the rat posterior cortex: II. Contributions of visual and ideothetic information to the directional firing. Experimental Brain Research, 101, 24-34.

Chen, L. L., Lin, L.-H., Green, E. J., Barnes, C. A., \& McNaughton, B. L. (1994). Head-direction cells in the rat posterior cortex: I. Anatomical distribution and behavioral modulation. Experimental Brain Research, 101, 8-23.

Chen, L. L., \& WISE, S. P. (1995a). Neuronal activity in the supplementary eye field during acquisition of conditional oculomotor associations. Journal of Neurophysiology, 73, 1101-1121.
Chen, L. L., \& WiSe, S. P. (1995b). Supplementary eye field contrast with the frontal eye field during acquisition of conditional oculomotor associations. Journal of Neurophysiology, 73, 1122-1134.

CHEN, L. L., \& WISE, S. P. (1996). Evolution of directional preferences in the supplementary eye field during acquisition of conditional oculomotor associations. Journal of Neuroscience, 16, 3067-3081.

Chen, L. L., \& Wise, S. P. (1997). Conditional oculomotor learning: Population vectors in the supplementary eye field. Journal of Neurophysiology, 78, 1166-1169.

Cho, Y. H., \& Kesner, R. P. (1996). Involvement of entorhinal cortex or parietal cortex in long-term spatial discrimination memory in rats: Retrograde amnesia. Behavioral Neuroscience, 110, 436-442.

Crowne, D. P., Richardson, C. M., \& Dawson, K. A. (1986). Parietal and frontal eye field neglect in the rat. Behavioural Brain Research, 22, 227-231.

DiMattia, B. V., \& Kesner, R. P. (1988a). Role of the posterior parietal association cortex in the processing of spatial event information. Behavioral Neuroscience, 102, 397-403.

DiMATTIA, B. V., \& KeSNER, R. P. (1988b). Spatial cognitive maps: Differential role of parietal cortex and hippocampal formation. Behavioral Neuroscience, 102, 471-480.

Duhamel, J.-R., Bremmer, F., BenHamed, S., \& Graf, W. (1997). Spatial invariance of visual receptive fields in parietal cortex neurons. Nature, 389, 845-848.

Fukushima, K. (1997). Corticovestibular interactions: Anatomy, electrophysiology, and functional considerations. Experimental Brain Research, 117, 1-16.

Galletti, C., Battaglini, P. P., \& Fattori, P. (1993). Parietal neurons encoding spatial locations in craniotopic coordinates. Experimental Brain Research, 96, 221-229.

GoOdAle, M. A., \& Milner, A. D. (1992). Separate visual pathways for perception and action. Trends in Neurosciences, 15, 20-25.

HYVÄRINEN, J. (1982). The parietal cortex of monkey and man. Berlin: Springer-Verlag.

Jeannerod, M., Arbib, M. A., Rizzolatti, G., \& SaKata, H. (1995). Grasping objects: The cortical mechanisms of visuomotor transformation. Trends in Neurosciences, 18, 314-320.

KAMETANI, H., \& KeSNER, R. P. (1989). Retrospective and prospective coding of information: Dissociation of parietal cortex and hippocampus. Behavioral Neuroscience, 103, 84-89.

Keshner, F. A., \& Peterson, B. W. (1995). Mechanisms controlling human head stabilization: I. Head-neck dynamics during random rotations in the horizontal plane. Journal of Neurophysiology, 73, 22932301.

Kesner, R. P., Farnsworth, G., \& DiMatita, B. V. (1989). Double dissociation of egocentric and allocentric space following medial prefrontal and parietal cortex lesions in the rat. Behavioral Neuroscience, 103, 956-961.

Kesner, R. P., FARnsworth, G., \& Kametani, H. (1992). Role of parietal cortex and hippocampus in representing spatial information. Cerebral Cortex, 1, 367-373.

Knierim, J. J., Skaggs, W. E., Kudrimoti, H. S., \& McNaughton, B. L. (1996). Vestibular and visual cues in navigation: A tale of two cities. In S. M. Highstein, B. Cohen, \& J. A. Buttner-Ennever (Eds.), New directions in vestibular research (Annals of the New York Academy of Sciences, Vol. 781, pp. 399-406). New York: New York Academy of Sciences.

KolB, B. (1990). Posterior parietal and temporal association cortex. In B. Kolb \& R. C. Tees (Eds.), The cerebral cortex of the rat (pp. 459471). Cambridge, MA: MIT Press.

Kolb, B., Buhrmann, K., McDonald, R., \& Sutherland, R. J. (1994). Dissociation of the medial prefrontal, posterior parietal, and posterior temporal cortex for spatial navigation and recognition memory in the rat. Cerebral Cortex, 4, 664-680.

KOLB, B., \& WALKEY, J. (1987). Behavioural and anatomical studies of the posterior parietal cortex in the rat. Behavioural Brain Research, 23, 127-145.

KRIEG, W. J. S. (1946). Connections of the cerebral cortex: I. The albino rat: A. Topography of the cortical areas. Journal of Comparative Neurology, 84, 221-275. 
LONG, J. M., \& KESNER, R. P. (1996). The effects of dorsal versus ventral hippocampal, total hippocampal, and parietal cortex lesions on memory for allocentric distance in rats. Behavioral Neuroscience. 110, 922-932.

MCClelland, J. L., MCNaughton, B. L., \& O’Reilly, R. C. (1995). Why there are complementary learning systems in the hippocampus and neocortex: Insights from the successes and failures of connectionist models of learning and memory. Psychological Review, 102, 419-457.

MCDANIEL, W. F., \& SKeEL, R. L. (1993). Visual-spatial functions persist following temporal and posterior parietal cortex lesions in rat. Physiology \& Behavior, 53, 199-203.

McNaughton, B. L., Barnes, C. A., Gerrard, J. L., Gothard, K., JunG, M. W., KNierim, J. J., Kudrimoti, H., QIN, Y., SKAGgS, W. E., SUSTER, M., \& WEAVER, K. L. (1996). Deciphering the hippocampal polyglot: The hippocampus as a path integration system. Journal of Experimental Biology, 199, 173-185.

McNaughton, B. L., Chen, L. L., \& Marcus, E. J. (1991). "Dead reckoning," landmark learning, and the sense of direction: A neurophysiological and computational hypothesis. Journal of Cognitive Neuroscience, 3, 190-202.

MCNaughton, B. L., Mizumori, S. J., Barnes, C. A., Leonard, B. J., MARQUIS, M., \& GREEN, E. J. (1994). Cortical representation of motion during unrestrained spatial navigation in the rat. Cerebral Cortex, 4, 27-39.

MiLleR, M. W., \& Vogt, B. A. (1984). Direct connections of rat visual cortex with sensory, motor, and association cortices. Journal of Comparative Neurology, 226, 184-202.

MiTZ, A. R., Godschalk, M., \& WiSE, S. P. (1991). Learning-dependent neuronal activity in the premotor cortex of rhesus monkeys. Journal of Neuroscience, 11, 1855-1872.

MiYashita, K., SaKaI, K., \& Hikosaka, O. (1996). Effects of SMA and pre-SMA inactivation on learning of sequential movements in monkey. Society for Neuroscience Abstracts, 22, 1862.

MizUmoRi, S. J. Y., \& Williams, J. D. (1993). Directionally selective mnemonic properties of neurons in the lateral dorsal nucleus of the thalamus of rats. Journal of Neuroscience, 13, 4015-4028.

Mountcastle, V. B., Lynch, J. C., Georgopoulos, A., Sakata, H., \& ACuna, C. (1975). Posterior parietal association cortex of the monkey: Command function for operations with extrapersonal space. Journal of Neurophysiology, 38, 871-908.

Nakamura, K., Miyamoto, S., Kinoshita, N., \& Ohzawa, K. (1997). Parietal neural network model simulating head centered object representation. Society for Neuroscience Abstracts, 23, 1589.

Nakamura, K., ONO, T., IsaJI, T., \& Yoshida, M. (1995). Parietal neural activity of awake rats during directional delayed nonmatching to sample task in familiar and unfamiliar conditions. Society for Neuroscience Abstracts, 21, 1216.

NAKAMURA, K., \& TAKaRAJIMA, A. (1996). Recognition of pattern position and shape by population vector in the spatial spreading associative neural network. In IEEE International Conference on Evolutionary Computation (pp. 780-785).

Neafsey, E. J., Bold, E. J., Hass, G., Hurley-Gius, K. M., Quirk, G., Sievert, C. F., \& TerReberRY, R. R. (1986). The organization of the rat motor cortex: A microstimulation mapping study. Brain Research Review, 11, 77-96.

O'KeEFE, J., \& DosTrovsKY, J. (1971). The hippocampus as a spatial map: Preliminary evidence from unit activity in the freely-moving rat. Brain Research, 34, 171-175.

Olavarria, J., \& Montero, V. M. (1981). Reciprocal connections between the striate and extrastriate cortical visual areas in the rat. Brain Research, 217, 358-363.

Olton, D. S., \& SAMUELSON, R. J. (1976). Remembrance of places: Spatial memory in rats. Journal of Experimental Psychology: Animal Behavior Processes, 2, 97-116.

Peterson, B. W., Baker, J. F., Perlmutter, S. I., \& Iwamoto, Y.
(1992). Neuronal substrates of spatial transformations in vestibuloocular and vestibulocollic reflexes. In B. Cohen, D. L. Tomko, \& F. E. Guedry (Eds.), Sensing and controlling motion: Vestibular and sensorimotor (Annals of the New York Academy of Sciences, Vol. 656, pp. 485-499). New York: New York Academy of Sciences. Poucet, B., \& Benhamou, S. (1997). The neuropsychology of spatial cognition in the rat. Critical Review in Neurobiology, 11, 101-120.

Pouget, A., \& Sejnowski, T. J. (1997). Spatial transformation in the parietal cortex using basis functions. Journal of Cognitive Neuroscience, 9, 222-237.

RANCK, J. B. (1984). Head-direction cells in the deep layer of dorsal presubiculum in freely moving rats. Society for Neuroscience $A b$ stracts, 10, 599.

Reep, R. L., Chandler, H. C., King, V., \& Corwin, J. V. (1994). Rat posterior parietal cortex: Topography of corticocortical and thalamic connections. Experimental Brain Research, 100, 67-84.

Sakata, H., Taira, M., Kusunoki, M., Murata, A., \& Tanaka, Y. (1997). The TINS Lecture: The parietal association cortex in depth perception and visual control of hand action. Trends in Neurosciences, 20, 350-367.

Sanchez, R. F., Montero, V. M., Espinoza, S. G., Diaz, E., CanITROT, M., \& Pinto-HAMUY, T. (1997). Visuospatial discrimination deficit in rats after ibotenate lesions in anteromedial visual cortex. Physiology \& Behavior, 62, 989-994.

SAVE, E., \& Moghaddam, M. (1996). Effects of lesions of the associative parietal cortex on the acquisition and use of spatial memory in egocentric and allocentric navigation tasks in the rat. Behavioral Neuroscience, 110, 74-85.

Save, E., Poucet, B., Foreman, N., \& Buhot, M.-C. (1992). Object exploration and reactions to spatial and nonspatial changes in hooded rats following damage to parietal cortex or hippocampal formation. Behavioral Neuroscience, 106, 447-456.

SNyder, L. H., Batista, A. P., \& Andersen, R. A. (1997). Coding of intention in the posterior parietal cortex. Nature, 386, 167-170.

Stackman, R. W., \& Taube, J. S. (1997). Firing properties of head direction cells in the rat anterior thalamic nucleus: Dependence on vestibular input. Journal of Neuroscience, 17, 4349-4358.

Tanaka, K., Hikosaka, K., Saito, H., Yukie, M., Fukada, Y., \& IWAI, R. (1986). Analysis of local and wide-field movements in the superior temporal visual areas of the macaque monkeys. Journal of Neuroscience, 6, 134-144.

Taube, J. S., Muller, R. U., \& Ranck, J. B. (1990). Head-direction cells recorded from the postsubiculum in freely moving rats: II. Effects of environmental manipulations. Journal of Neuroscience, 10 , 436-447.

TOLDI, J., FoHER, O., \& WolfF, J. R. (1986). Sensory interactive zones in the rat cerebral cortex. Neuroscience, 18, 461-465.

VoGt, B. A., \& Miller, M. W. (1983). Cortical connections between rat cingulate cortex and visual, motor, and postsubicular cortices. Journal of Comparative Neurology, 216, 192-210.

Wise, S. P., ChEN, L. L., \& Dominey, P. F. (1996). Neural activity during associative motor learning. In M. Ito \& Y. Miyashita (Eds.), Integrative and molecular approach to brain function (pp. 271-283). Amsterdam: Elsevier.

WisE, S. P., \& DONOGHUE, J. P. (1986). Motor cortex of rodents. In E. G. Jones \& A. Peters (Eds.), Cerebral cortex: Sensorimotor areas and aspects of cortical connectivity (pp. 243-270). New York: Plenum.

ZILLES, K. (1985). The cortex of the rat: A stereotaxic atlas. Berlin: Springer-Verlag

ZILLES, K. (1990). Anatomy of the neocortex: Cytoarchitecture and myeloarchitecture. In B. Kolb \& R. C. Tees (Eds.), The cerebral cortex of the rat (pp. 76-112). Cambridge, MA: MIT Press.

(Manuscript received December 22, 1997; revision accepted for publication February 26, 1998.) 